\title{
Prevalence of Besnoitiosis and Associated Histopathological Changes Amongst Apparently Healthy Cattle and Goats at Slaughter in Maiduguri Central Abattoir, Borno State, North Eastern Nigeria
}

\author{
*M. K. Zango ${ }^{1}$, S. A. Malgwi ${ }^{1}$, F. Kyari ${ }^{1}$, A. W. Mbaya ${ }^{1}$, A. A. Biu ${ }^{1}$ and S. J. \\ Badau $^{2}$ \\ ${ }^{I}$ Department of Veterinary Microbiology and Parasitology, Faculty of Veterinary Medicine, University of \\ Maiduguri, Maiduguri, Nigeria \\ ${ }^{2}$ Department of Veterinary Pathology, Faculty of Veterinary Medicine, University of Maiduguri, Maiduguri, \\ Nigeria
}

\begin{abstract}
This study was conducted to investigate the prevalence of besnoitiosis and associated histopathological changes amongst apparently healthy cattle and goats at slaughter in Maiduguri central abattoir Borno state, Nigeria. A total of 100 skin sections each, from the neck region were randomly collected, preserved in $10 \%$ formalin and later taken to the laboratory and subjected to histopathology to detect Besnoitia cysts and associated histopathological changes. This study revealed an overall prevalence of $2 \%$ in cattle. Out of the 100 skin sectionsexamined from cattle, 38 were from bulls and 62 were from cows. Of the 38 skin sections from bulls examined, 2(5.3\%) were positive for Besnoitia cyst and none (0\%) was positive for the cow's $(P>0.05)$. Similarly, of the 100 skin sections examined, 80 were from Wadara breed and 20 from Red bororo. Out of the 80 skin sections examined from Wadara breed, 2(2.5\%) were positive for Besnoitia cyst and none $(0 \%)$ was positive for Red bororo $(P>0.05)$. However, out of 100 skin sections from goats examined, none was positive for Besnoitia cysts revealing $0 \%$ prevalence.All the skin sections sampled and examined were from adult cattle and goats. Out of the 100 skin sections examined from the adult cattle, 2(2.0\%) were positive for Besnoitia cysts. A skin section examined from Wadara breed showed localized area of suppurative dermatitis in the dermis of the skin characterized by massive neutrophilic infiltrations. This is the first report showing the prevalence of besnoitiosis in apparently healthy cattle and goats in Borno state, north eastern Nigeria.
\end{abstract}

Keywords: Besnoitiosis, Borno State, Cattle and goats, Nigeria, Prevalence

\section{Introduction}

Besnoitiosis also referred to as bovine elephantiasis and bovine anasarque, is an acute or chronic disease caused by a coccidian protozoan of the genus Besnoitia. It affects a wide range of domestic and wildlife [1], [2], and [3]. The lifecycle involves a definitive host and an intermediate host and there are seven classified species of which three occur in domestic livestock. The species are Besnoitiabesnoiti in cattle, B. caprae in goats, and B. benneti in horses, donkeys and mules. The other four Besnoitia species infect wildlife species [4]. Besnoitia are host specific and B.caprae does not infect sheep [4]. Cats are the definitive host for some Besnoitia infecting wildlife but the definitive host(s) for the three domestic livestock species are not known [5], [6], [7] and [4].

Besnoitiosis in livestock occurs as outbreaks in some tropical and subtropical regions and sporadically in other areas and in endemic areas, the disease can affect large proportion of the herd and cause significant economic losses [4]. Bovine besnoitiosis has been described in sub-saharan Africa (South Africa, Swaziland, Boswana, Namibia, Zimbabwe, Angola, Congo, Kenya, Uganda, Tanzania, Cameroon, Sudan, Nigeria), Asia (Israel, Russia, South Korea) western and central Europe [8], [9], [10], [11], [12], [13], [14] and [15].

The natural means of transmission is not known, but is presumed to be by ingestion of oocysts from the definitive host(s). Infection with $B$. besnoiti and B. caprae can be transmitted experimentally with endozoites and bradyzoites, and mechanically by infections or by biting flies [4]. The role of a carnivorous definitive host in the epidemiology of bovine besnoitiosis remains to be elucidated. Wild ruminants and probably rodents should not be disregarded as reservoirs of the parasites [13] and [16]. however, as at present, bovine besnoitiosis has not been reported to infect man [17].

Clinical cases appear in two distinct stages; the acute anarsarca stage and chronic scleroderma stages, with cysts developing in many predominantly superficial tissues [18]. Thickening of the skin (Elephant skin disease) over the lower limbs, around the eyes, nose, face and scrotum, alopecia in all of these areas and white granular cysts in the sclero-conjuctiva can be seen [19]. Infection can also occur in a sub-clinical form, with its 
only overt sign being the occurrence of parasitic cysts in the sclera, skin and conjunctiva [18] Recent epidemiological data confirm an increased number of cases and geographical expansion of besnoitiosis in the European Union Member States (EU MS), therefore bovine besnoitiosis should be considered an emerging disease in the EU [17]. However, there is paucity of information on the prevalence of besnoitiosis in Nigeria in general. Thus, this study was undertaken to determine the prevalence of besnoitiosis and associated histopathological changes amongst apparently healthy cattle and goats at slaughter in Maiduguri Central Abattoir, Borno state, North eastern Nigeria.

\section{Study area}

\section{Materials And Methods}

The study was conducted was in Maiduguri the capital of Borno State, Nigeria located between latitude $11^{\circ} 5^{1}$ and $12^{\circ} \mathrm{N}$ and longitude $13^{\circ} 5^{1}$ and $14^{\circ} \mathrm{E}$ at about $354 \mathrm{~m}$ above sea level with an ambient temperature of $40-$ $45^{\circ}$ [20]. The range of $30-50 \%$ is the mean relative humidity of Maiduguri with the minimum been experienced in February and March when it drops to as low as $10 \%$ and reaches maximum in August when it rises to as high as $90 \%$ [21]. The abattoir was established in 1957 for the purpose of providing wholesome meat for human consumption. It is located around kasuwanshanu area in Maiduguri [22].

\section{Sample Size Estimation}

The sample size was determined using the formula of [23] using a previous prevalence of $6.7 \%$ [24], and the calculated sample size was 96 samples, for more precision 100 skin sections samples each were collected from cattle and goats.

\section{Sample Collection}

A total of 100 skin sections each were obtained from apparently healthy cattle and goats at slaughter, around the neck region, measuring about 1 by $1 \mathrm{~cm}$ each without any clinical manifestation of infection. A simple random sampling technique was employed; samples obtained were preserved in $10 \%$ formalin and transported to the Parasitology Laboratory of the Department of Veterinary Microbiology and Parasitology, University of Maiduguri for processing.

\section{Histopathology}

The samples were sectioned at $5 \mu \mathrm{m}$ thickness using a rotary microtome, the sectioned skins were dehydrated in ascending grades of alcohol (70\%,80\%,90\% and 100\%), and later stained with haematoxylin and eosin stain [25]. The stained skin sections were examined microscopically for the presence of Besnoitia cysts containing basophilic granuled bradyzoites [26] and associated histopathological lesions.

\section{Statistical analysis}

Data obtained was presented in simple percentages using chi-square [27].

\section{Results}

The prevalence of besnoitiosis in cattle according to sex in Maiduguri central abattoir, Borno state, northeastern Nigeria is presented in Table 1 . Out of the total of 100 skin sections examined, only $2(2.0 \%)$ were positive. However, out of the 100 skin sections sampled, 38 were from bulls and 62 from cows. Of the 38 skin sections from bulls examined, 2(5.3\%) were positive for Besnoitia cyst and none (0\%) was positive for the cows. There was no statistical variation in the prevalence rate between sexes ( $p>0.05)$. Table 2 shows the prevalence of besnoitiosis in cattle according to age in Maiduguri central abattoir, Borno state, northeastern Nigeria. All the 100 skin sections sampled were from adult cattle none was from young. Out of the 100 skin sections examined from the adults, $2(2.0 \%)$ were positive for Besnoitia cysts.

Table 3 shows the prevalence of besnoitiosis in cattle according to some breeds in Maiduguri central abattoir, Borno state, northeastern Nigeria. Out of the 100 skin sections sampled, 80 were from Wadara breed and 20 from Red bororo. Out of the 80 skin sections examined from Wadara breed, 2(2.5\%) were positive for Besnoitia cyst and none (0\%) was positive for Red bororo. Similarly, There was no statistical variation in the prevalence rate between breeds ( $\mathrm{p}>0.05)$.

Tables 4, 5 and 6 show the prevalence of besnoitiosis in goats according to sex, age and some breeds respectively. None ( $0 \%)$ of the skin sections of the goats examined were positive for Besnoitia cysts.

Figure one (Fig.1) shows photomicrograph of a Besnoitia cyst encountered in the dermis of the skin section of wadara cattle. Figure two (Fig.2) shows photomicrograph showing localized area of suppurative dermatitis in the dermis of the skin of wadara cattle characterized by massive neutrophil infiltration 


\section{Discussion}

This study on the prevalence of besnoitiosis and associated histopathological changes amongst apparently healthy cattle and goats at slaughter in Maiduguri Central Abattoir, Borno state north eastern Nigeria revealed a prevalence of $2.0 \%$ in cattle, following the occurrence of Besnoitia cysts from various skin sections examined. This is in agreement with the work of [24] in the same study area, who reported a higher prevalence of $6.7 \%$ following the occurrence of Besnoitia cysts in pachydermatous skin lesions of two cattle (wadara), which showed symptoms of clinical cutaneous besnoitiosis in the study area. The variation between the study conducted by [24] and this present study is that the former, worked on clinically infected cattle, while in this present study apparently healthy cattle and goats were examined which might have accounted for the lower prevalence rate recorded.

Similarly an in-apparent form of besnoitiosis was reported in Nigerian cattle, which had neither clinical signs nor gross lesions suggestive of the disease, but Besnoitia cysts were found in skin sections [28]. However, this is in consonance with the present study carried out amongst apparently healthy animals, no clinical signs or skin lesions were observed prior to laboratory examination of skin sections but revealed the presence of Besnoitia cysts.

In this study, only bulls (5.3\%) revealed the presence of Besnoitia cysts which is contrary to the findings of [24], who recorded $13.6 \%$ and $2.7 \%$ prevalence in bulls and cows respectively. [29], also reported the first incidence of caprine besnoitiosis in female goats (does) in a study conducted in Anchau area of Kaduna state. Similarly, in this study, only skin sections from the Wadara breed of cattle were positive for Besnoitia cysts and this is in consonance with the work of [24] who also reported only positive cases from Wadara breed of cattle. This could possibly be due to the susceptibility of the Wadara breed to bovine besnoitiosis as suggested by [24]. In this study only skin sections from adult cattle and goats were sampled and examined which revealed $2 \%$ prevalence in adult cattle only. This is due to the fact that animals slaughtered in the abattoir during the period of this investigation were adults; young ones are only slaughtered as a result of serious trauma or ailment with poor prognosis. However, [8] reported that there is a relationship between the age of the animal and the epidemiology of the disease. He further stated that in a study conducted on a farm where the disease was present, the highest incidence of infection was detected in adult animals but was rarely encountered in calves less than 6 months of age. Histopathologically, a skin section examined from wadara breed showed localized area of suppurative dermatitis in the dermis of the skin characterized by massive neutrophil infiltration which is suggestive of secondary bacterial infection [30].

\section{Conclusion}

In conclusion, Besnoitia cysts were identified in an apparent or sub-clinical form exclusively in the Wadara bulls. This study therefore provided base line information on the prevalence of the infection amongst sex, age and some breeds of cattle and goats in the study area.

\section{References}

[1]. Marotel, M. (1912). Discussion of paper by Besnoit e Robin. Bull. et Mem. de la Soc. des Sciences Vet. de lyon et de la soc. de Med. vet. de lyon e du sud-Est 15, 196-217.

[2]. Bigalke, R. D. (1968). New concepts on the epidemiology features of bovine besnoitiosis as determined by laboratory and field investigations. onderstepoort journal of veterinary research 34(2), 303-316.

[3]. Soulsby, E. J. L. (1982). Helminths, Arthropods and Protozoa of domesticated animals. 7th ed.

[4]. Radostits, M. O., Blood, D. C., Gay, C. C., Hinchcliff, K. W., Eds. (2000). A text book of diseases of cattle, Pigs, sheep, goats and horses. 9th ed.

[5]. Wallace, G. D., Frenkel, J. K. (1975). Besnoitia species (protozoa, sporozoa, toxoplasmatidae): recognition of cycle transmission by cats. Science. 1975 April 25, 369-71.

[6]. Dubey, J. P. (1977). Toxoplasma,Hammondia,Besnoitia,Sacorcystis and other tissue cyst formation coccidia of man and animals. In: Parasitic protozoa. kreier Journal of parasitology 3.

[7]. Rommel, M. (1978). Vergleichende Darstellung der Entwicklungsbiologic der Gattungen Sarcocystis, Frenkelia, Isospora, Cystoisospora, Hammondia, Toxoplasma and Besnoitia. Zeitschrift fur Parasitenkunde 57, 269-283.

[8]. Bigalke, R. D. (1981). Besnoitiosis and Globidiosis. In:Ristic,M.,Mclntyre,I.(Eds),Diseases of cattle in the tropics. Manurus Nijhoff, The Hague, The Netherlands, 429-442.

[9]. Juste, R. A., Cuervo, L. A., Marco, J. C., Oregui, L. M. (1990). La besnoitiosis bovina:desconocida en Espana? Medical Veterinary 7(11), 613-618.

[10]. Cortes, H. C., Vindal, R., Reis, Y. (2004). Bovine besnoitiosis,one approach for a better understanding of its importance in Portugal. Proceeding of 23rd World Buiatrics congress, 35-6.

[11]. Cortes, H. C., Leitao, A., Vila-Vicosa, M. J., Ferreira, M. L., Caeiro, V., Hjerpe, C. A. (2005). Besnoitiosis in bulls in Portugal. Veterinary Record 157(9), 262-4.

[12]. Alzieu, J. P. (2007). Re-emerging Cattle besnoitiosis (Besnoitia besnoiti) in France: Update on clinical and epidemiological aspects. 21st International conferences WAAVP,Gant (Belgium), , Pp.222.

[13]. Castillo, J. A., Marcan, J. M., Ortega-Mora, L. M., Alvarez-Garcia, G. (2009). La besnoitiosis bovina,Presentada como una enfermedad emergenta europea. Albeitar 127, 24-25.

[14]. Fernandez-Garcia, A., Risco-Castillo, V., Pedraza-Diaz, S., Aguado-Martinez, A., Alvarez-Garcia, G., Gomez-Bautista, M., Collantes-Fernandez, E., Ortega-Mora, L. (2009). First isolation of Besnoitiabesnoiti from a chronically infected cow in Spain. Journal of Parasitology 95(2), 474-476. 
[15]. Zacarias, J. A. (2009). Epidemiologia(Seroprevalencia y Vectores) de la Besnoitiosis bovina de las Sierras de Urbasa y Andia. Doctoral Thesis. University of Zaragoza.

[16]. Melhorn, H., Klimpsel, S., Schein, E., Heydorn, A. O., Al-Quraishy, S., Selmair, J. (2009). Another African disease in central Europe: Besnoitiosis of cattle.I. Light and electron microscopical study. Parasitol. Res.

[17]. European Food Safety Authority (EFSA) (2010). Bovine Besnoitiosis: An emerging disease in Europe. EFSA Journal 8(2), 1499.

[18]. Oryan, A., Namazi, F., Silver, I. A. (2011). Histological and ultrastructure studies on experiementalcaprinebesnoitiosis veterinary pathology 48, 1094-1100.

[19]. Oryan, A., Azizi, S. (2008). Ultrastructure and pathology of Besnoitia caprae in the naturally infected goats of Kerman,East of Iran. Journal of Parasitology research 102, 1171-1176.

[20]. Alaku, S. O. (1983). Body and carcass losses in goats during advance period of West African Sahelian dry season. World Review of Animal Production 19: 49-54.

[21]. Ugherughe, P. O. and Ekedohun, P. A. (1986).Pasture and rangeland potentials. Annals of Borno, 3: $179-192$.

[22]. Ibrahim, M. B., Okon, K. O., Adamu, N. B., Askira, U. M., Isyaka, T. M., Adamu, S. B., and Mohammed, A. (2011).Methicilinresistant Staphylococcus aureus (MRSA) Colonization rate among ruminants animals slaughtered for human consumption and contact persons in Maiduguri, Nigeria, African Journal of Microbiology Research.Vol. 8.

[23]. Thrusfield, M., Ed. (2005). Veterinary epidemiology. 3rd edition ed. Oxford UK: Blackwell science.

[24]. Igbokwe, I. O., Abba, Y., Nwagbara, N. D. (2009). Prevalence of Besnoitia Cysts in Pachydermatous Skin Lesions of Cattle in Northeastern Nigeria. Nigerian Journal of Experimental and Applied Biology 10(1), 31-36.

[25]. Drury, R. A. B., Wallington, E. A., Eds. (1976). Carleton's Histological Technique. 4th ed. London: Oxford University press

[26]. Bigalke, R. D., Prozesky, L. (2004). Besnoitiosis. In: Infectious Disease of Livestock. Vol. 1. Cape Town, South Africa: Oxford University press.

[27]. Graphpad® Instat (2000). Version 3.00 for windows, Graphpad Software, San Diego, CA, USA, Www.Graphpad.Com.

[28]. Oduye, O. O. (1974). Occurrence of inapparent cutaneous besnoitiosis in cattle in Nigeria. Journal of Nigerian veterinary Medical Association 3, 92-96.

[29]. Sambo, S. J., Ibrahim, N. G. D., Esievo, K. A. N., Hambolu, J. O., Makoshi, M. S., Tekdek, L. B. (2007). First Incidence of Caprine Besnoitiosis in Kaduna State Nigeria. Journal of Animal and Veterinary Advances 6(5), 673-675.

[30]. McGavin, M. D and Zachary, J. F. (2012). Pathologic Basis of Veterinary Disease. $5^{\text {th }}$ ed. Elsevier Mosby. Pp 118-119. ISBN: 9780-323-07533-6.

Table 1: prevalence of besnoitiosis in cattle according to sex in Maiduguri Central Abattoir, Borno state, northeastern Nigeria

\begin{tabular}{|lcc|}
\hline Sex & No. Examined & No. Positive $(\%)$ \\
\hline Male (Bulls) & 38 & $2(5.3)^{\mathrm{a}}$ \\
Female (Cows) & 62 & $0(0.0)^{\mathrm{a}}$ \\
\hline Total & 100 & $2(2.0)$ \\
\hline
\end{tabular}

Numbers with same superscripts in 3rd column did not differ significantly $(\mathrm{P}>0.05)$ : chi-square

Table 2: Prevalence of besnoitiosisin cattle according to age in Maiduguri Central Abattoir, Borno state, northeastern Nigeria

\begin{tabular}{|lcc|}
\hline Age & No. Examined & No. Positive $(\%)$ \\
\hline Adult & 100 & $2(2.0)^{\mathrm{a}}$ \\
Young & 0 & $0(0.0)^{\mathrm{a}}$ \\
\hline Total & 100 & $2(2.0)$ \\
\hline
\end{tabular}

Numbers with same superscripts in 3rd column did not differ significantly $(\mathrm{P}>0.05)$ : chi-square

Table 3: Prevalence of besnoitiosis in cattle according to some breeds in Maiduguri Central Abattoir, Borno state, northeastern Nigeria

\begin{tabular}{|lcc|}
\hline Breed & No. Examined & No. Positive $(\%)$ \\
\hline Wadara & 80 & $2(2.5)^{\mathrm{a}}$ \\
Red bororo & 20 & $0(0.0)^{\mathrm{a}}$ \\
\hline Total & 100 & $2(2.0)$ \\
\hline
\end{tabular}

Numbers with same superscripts in 3rd column did not differ significantly $(\mathrm{P}>0.05)$ : chi-square

Table 4: prevalence of besnoitiosis in goats according to sex in Maiduguri Central Abattoir, Borno state, northeastern Nigeria

\begin{tabular}{|lcc|}
\hline Sex & No. Examined & No. Positive (\%) \\
\hline Male (Buck) & 32 & $0(0.0)^{\mathrm{a}}$ \\
Female (Doe) & 68 & $0(0.0)^{\mathrm{a}}$ \\
\hline Total & 100 & $0(0.0)$ \\
\hline
\end{tabular}

Numbers with same superscripts in 3rd column did not differ significantly $(\mathrm{P}>0.05)$ : chi-square 
Prevalence of Besnoitiosis and Associated Histopathological Changes Amongst Apparently Healthy

Table 5: Prevalence of besnoitiosisin goats according to age in Maiduguri Central Abattoir, Borno state, northeastern Nigeria

\begin{tabular}{|lcc|}
\hline Age & No. Examined & No. Positive $(\%)$ \\
\hline Adult & 100 & $0(0.0)^{\mathrm{a}}$ \\
Young & 0 & $0(0.0)^{\mathrm{a}}$ \\
\hline Total & 100 & $0(0.0)$ \\
\hline
\end{tabular}

Numbers with same superscripts in 3rd column did not differ significantly $(\mathrm{P}>0.05)$ : chi-square

Table 6: Prevalence of besnoitiosis in goats according to some breeds in Maiduguri Central Abattoir, Borno state, northeastern Nigeria

\begin{tabular}{|lcc|}
\hline Breed & No. Examined & No. Positive $(\%)$ \\
\hline Sokoto red & 70 & $0(0.0)^{\mathrm{a}}$ \\
Borno white & 30 & $0(0.0)^{\mathrm{a}}$ \\
\hline Total & 100 & $0(0.0)$ \\
\hline
\end{tabular}

Numbers with same superscripts in 3rd column did not differ significantly $(\mathrm{P}>0.05)$ : chi-square

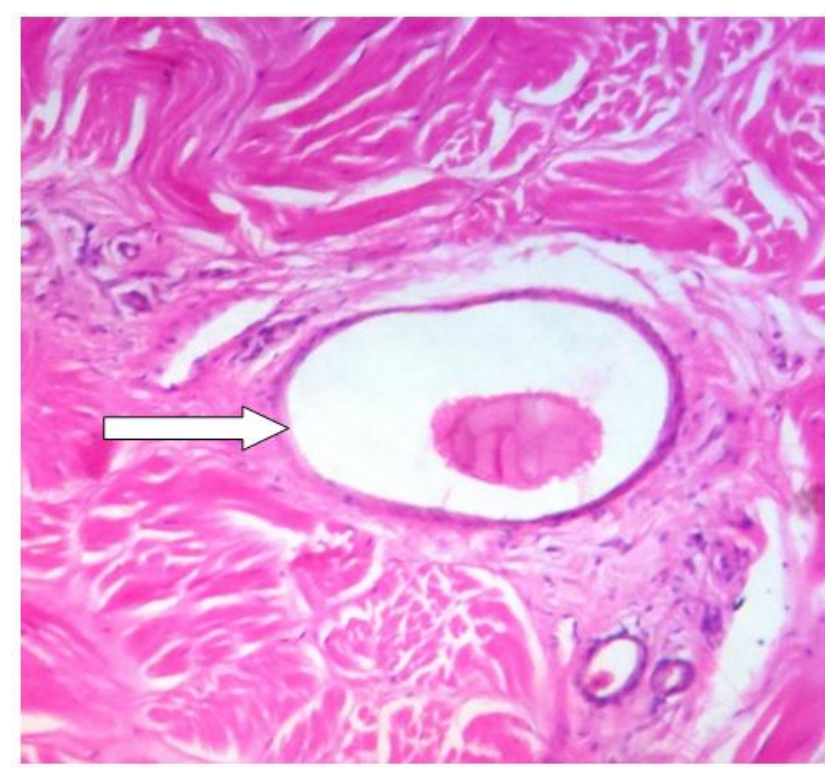

Fig. 1: Photomicrograph of a Besnoitia cyst encountered in the dermis of the skin section of wadara cattle (arrow), H \& E, X100.

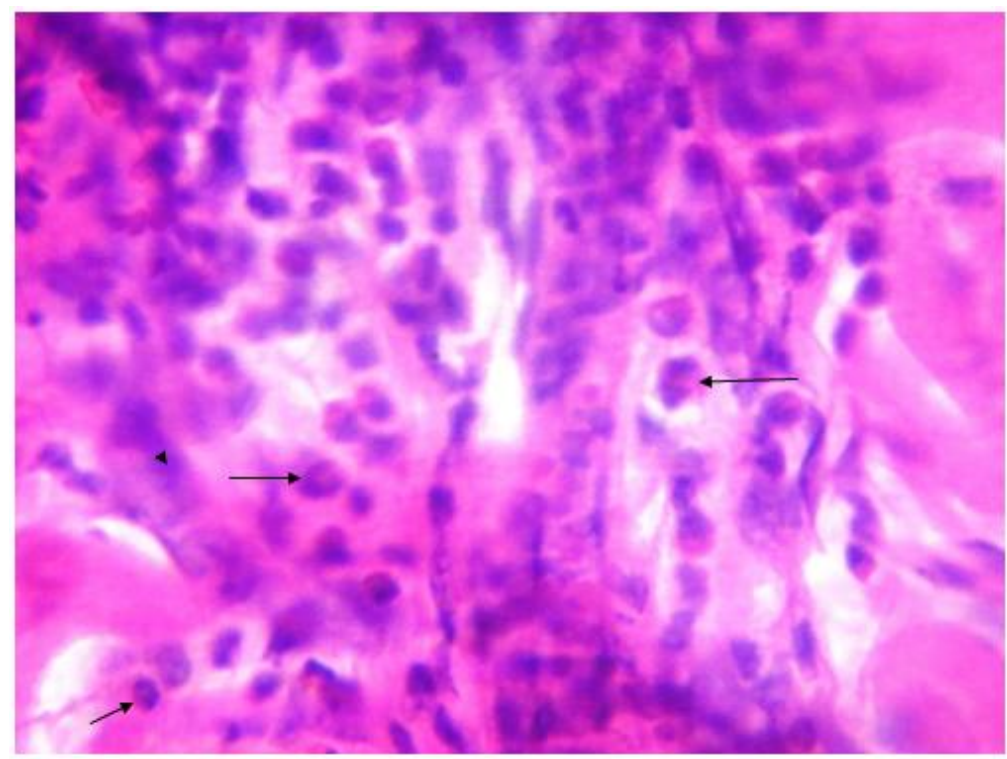

Fig. 2: Photomicrograph showing localized area of suppurative dermatitis in the dermis of the skin of wadara cattle characterized by massive neutrophil infiltration (arrows). H \& E, X400. 